\title{
Predictors of Delayed Diagnosis and Evolution in Sub-Saharan Immigrants with HIV Infection in a Hospital in Madrid (2004-2013)
}

\author{
Barrios Blandino $\mathrm{AM}^{* 1}$, San Martín López $\mathrm{JV}^{2}$, Ruiz-Giardin JM², García-Arata I ${ }^{3}$, Cabello Clotet N4, \\ Canalejo Castrillero $\mathrm{E}^{2}$ and Hinojosa Mena-Bernal J ${ }^{2}$
}

${ }^{1}$ Servicio de Medicina Interna-Infecciosas, Hospital Universitario de La Princesa, Madrid, Spain

${ }^{2}$ Servicio de Medicina Interna-Infecciosas, Hospital Universitario de Fuenlabrada, Madrid, Spain

${ }^{3}$ Servicio de Microbiología, Hospital Universitario de Fuenlabrada, Madrid, Spain

${ }^{4}$ Servicio de Medicina Interna-Infecciosas, Hospital Universitario Clínico San Carlos, Madrid, Spain

*Corresponding author: Barrios Blandino AM, Servicio de Medicina Interna-Infecciosas, Hospital Universitario de La Princesa, Calle Diego de León, 62 - 28006 Madrid- Spain, Fax: +34 915202 209, Tel: +34 91 5202200, E-mail: abarrios@salud.madrid.org

Citation: Barrios Blandino AM, San Martín López JV, Ruiz-Giardin JM, García-Arata I, Cabello Clotet N, et al. (2017) Predictors of Delayed Diagnosis and Evolution in Sub-Saharan Immigrants with HIV Infection in a Hospital in Madrid (2004-2013). J Aids Hiv Infe 3(1): 102

Received Date: February 14, 2017 Accepted Date: June 06, 2017 Published Date: June 08, 2017

\begin{abstract}
Objectives: The aim of this study was to analyze the delayed diagnosis and evolution of HIV infection in predominantly sub-Saharan immigrants compared to other patients in a hospital in Madrid between 2004 and 2013.

Methods: We retrospectively analyzed new HIV diagnoses. Late presentation or advanced disease were considered the presence of CD4 lymphocyte counts less than 350 or 200 cells/ $\mu$ at diagnosis, respectively, or an AIDS-defining disease regardless of the CD4 count. Patients were compared according to their origin and sex.

Results: Of the 219 newly diagnosed patients, 124 (57\%) were immigrants, 91 of which were (42\%) sub-Saharan in origin. Delayed diagnosis occurred in $62 \%$ and $43 \%$ of all patients with CD4 counts $<350$ or $<200$ cells/ $\mu$, respectively; these figures were higher in immigrant men (71\% and 61\%) and Spanish women (90\% and 64\%). The factors associated with a delayed diagnosis were an older age and status as a male immigrant with heterosexual transmission. The loss to follow-up was very important (33\%) and was associated with a younger age at diagnosis, heterosexual transmission, and being a male immigrant, especially sub-Saharan. The principal cause of the 7 deaths was opportunistic disease; four of these patients were recently diagnosed with CD4 counts $<50$ cells/ $\mu$ l.

Conclusions: Delayed diagnosis of HIV infection continues to be a significant problem in subpopulations with a low perception of risk (older patients and heterosexuals) or high vulnerability (sub-Saharan immigrants). The loss to follow-up was higher among the subSaharan immigrants. Prevention campaigns are necessary to increase the perception of risk in the general population (heterosexual transmission) and among the sub-Saharans.
\end{abstract}

Keywords: HIV; Immigration; Sub-Saharans; Late diagnosis; Mortality; Aids

\section{Introduction}

With the exponential growth of immigration in Spain over the last 20 years (12\% of the population as of January 1, 2013) [1], the proportion of immigrants among patients infected with human immunodeficiency virus (HIV) has increased [2]. This population comprised $37 \%$ of new diagnoses in 2011 [3].

Immigrants in the majority of studies (especially Africans) are diagnosed and begin treatment much later than the native populations [4-8]. This delayed diagnosis is also associated with the male sex, heterosexual transmission, intravenous drug use, and an older age at diagnosis [5-9]. Although the evolution of HIV infection does not seem to vary by origin, women and subSaharan Africans have been described as vulnerable populations [4,10]. Delayed diagnosis has a negative impact on individuals (poorer immunological recovery and greater morbimortality) [11,12] and on the community (increased HIV transmission). In Spain, $47 \%$ of the new diagnoses in 2011 were delayed, and $29 \%$ of the diagnoses were patients with advanced disease (CD 4 counts less than 350 and 200 cells/ $\mu$ l, respectively) [3].

Few studies have investigated HIV-infected sub-Saharan immigrants in Spain. The objective of our study was to evaluate the influence of immigration (predominantly sub-Saharan in our area) on delayed diagnosis, initiation of antiretroviral therapy, and mortality. 


\section{Material and Methods}

A retrospective analysis was performed with a database collected prospectively at the University Hospital of Fuenlabrada in Madrid. Data collected from January 1, 2004, through May 31, 2013, were analyzed. A total of 219 new HIV diagnoses were included in the analysis.

The following epidemiological variables were collected in each case: age at diagnosis, sex, date of diagnosis, country of origin, and route of HIV transmission. Additionally, laboratory and clinical variables were collected, including the first determination of the CD4 lymphocytes and HIV viral load, hepatitis C virus (HCV) and hepatitis B virus (HBV) serology, HLA B5701, HIV subtype, primary resistance mutations, AIDS-defining disease at diagnosis (in the first 6 months) and cause of death when appropriate.

\section{Definitions}

- Delayed diagnosis: Presence at diagnosis of CD4 lymphocyte counts less than 350 (late presentation) or 200 cells/ $\mu$ l (advanced disease) or an AIDS-defining disease regardless of the CD4 count in accordance with the European consensus [13].

- Delayed initiation of treatment: Treatment begun with a CD4 count less than 200 cells/ $\mu$ l.

- Loss to follow-up: Absence of analytical performance in the last year.

During the medical record review, patient confidentiality was respected and was veiled in compliance with Organic Law 15/1999 on the Protection of Personal Data and regulation 1720-2007.

\section{Statistical analysis}

A descriptive analysis of the variables was performed. Continuous variables were expressed as medians with their corresponding interquartile ranges, and categorical variables were expressed as numbers (absolute frequencies) and percentages (relative frequencies). The variables were compared according to the patient origin and gender. The Mann-Whitney test was used for the quantitative variables, and the Chi-square test and Fisher's exact test were applied as appropriate for the qualitative variables. A bivariate analysis was performed to identify factors associated with a delayed diagnosis and loss to follow-up; subsequently, a multivariate analysis was performed with the relevant variables $(\mathrm{p}<0.2)$ and the origin and sex variables. The logistic regression results were provided as odds ratios (ORs) with $95 \%$ confidence intervals (CIs). To analyze the loss to follow-up, survival curves (Kaplan-Meier method) were generated according to origin using the log rank test to compare the curves. The statistical analysis of the data was performed using SPSS (version 13.0) with a p value $<0.05$ considered statistically significant.

\section{Results}

\section{Epidemiological data and delayed diagnosis}

During the study period, 124 (57\%) of the 219 new diagnoses were immigrants, of which 91 (73.4\%) were from sub-Saharan Africa (SSA) (Table 1). The duration of the cohort monitoring was 669 patient-years, with a mean of 3 years of follow-up per patient. The epidemiological characteristics and delayed diagnosis of the study population according to origin and sex are shown in Table 2.

\begin{tabular}{|c|c|}
\hline Area of origin & N (\%) \\
\hline Africa & $95(76.6 \%)$ \\
\hline Nigeria & 45 \\
\hline Guinea & 29 \\
\hline Cameroon & 4 \\
\hline Morocco & 4 \\
\hline Angola & 3 \\
\hline Congo & 3 \\
\hline Ivory Coast & 2 \\
\hline Burundi & 1 \\
\hline Sierra Leona & 1 \\
\hline Sao Tome and Principe & 1 \\
\hline South Africa & 1 \\
\hline Latin America & $19(15.3 \%)$ \\
\hline Colombia & 6 \\
\hline Peru & 4 \\
\hline Cuba & 3 \\
\hline Ecuador & 3 \\
\hline
\end{tabular}




\begin{tabular}{|c|c|}
\hline Area of origin & $\mathbf{N}(\%)$ \\
\hline Venezuela & 2 \\
\hline Guatemala & 1 \\
\hline Others & $10(8.1 \%)$ \\
\hline Romania & 8 \\
\hline Poland & 1 \\
\hline Portugal & 1 \\
\hline
\end{tabular}

Table 1: Place of origin of immigrants with a new HIV diagnosis $(n=124)$

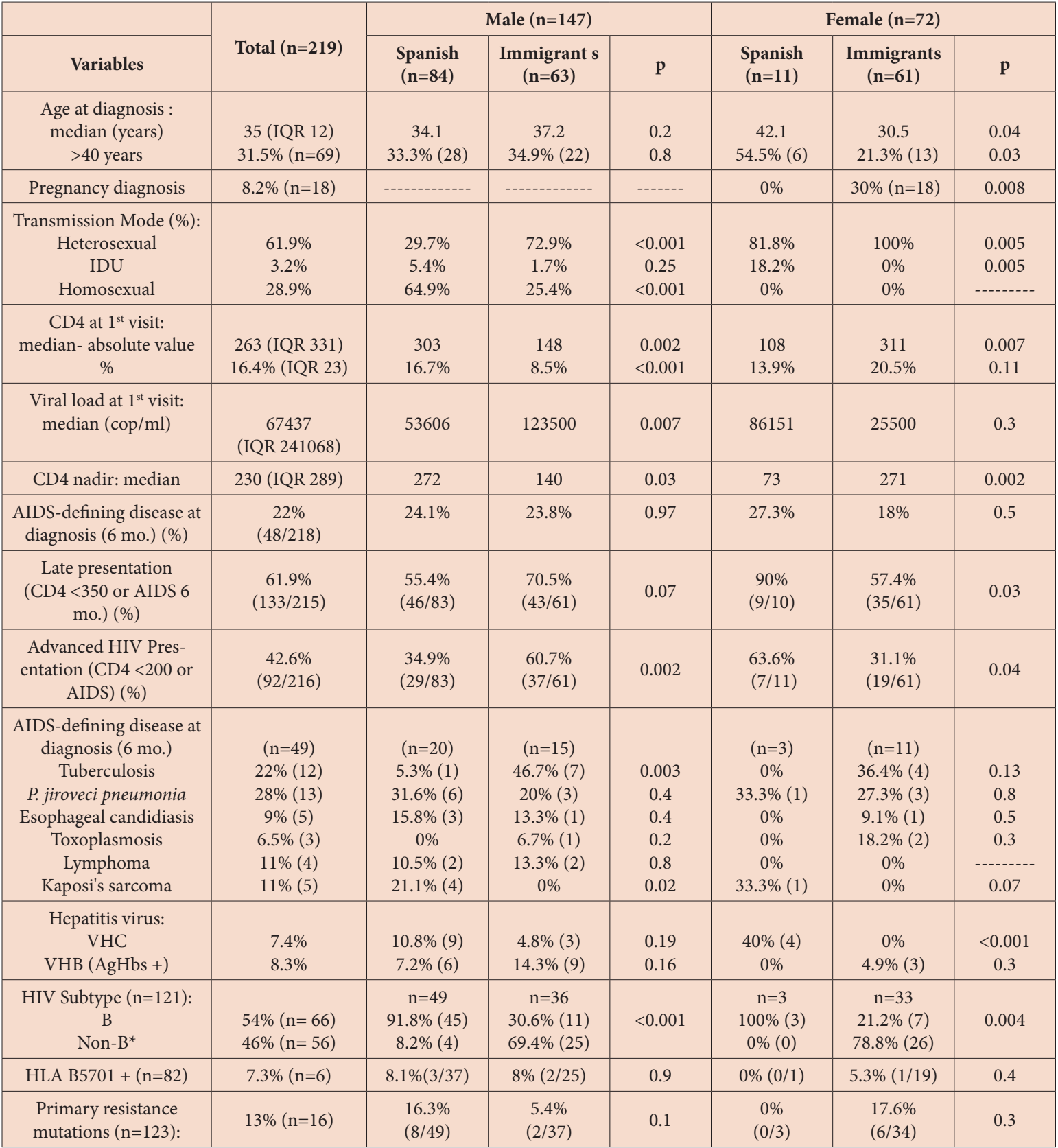

IQR: Interquartile range, IDU: Injection drug user

*The most frequent non-B subtypes were the recombinant CRF02_AG (52\%) and G subtypes (11\%)

Table 2: Epidemiology of patients with a new HIV diagnosis and delayed diagnosis stratified by sex and origin

\section{Sub-Saharan immigrants}

The proportion of women was higher in the group of sub-Saharan immigrants (59\% vs. $21 \%$ of the other immigrants and $12 \%$ among the Spaniards). Regarding the mode of transmission of the infection, heterosexual relations was the most common risk factor in the sub-Saharans (99\%) and the rest of the immigrants (48\%), whereas homosexual relations was the most common route in the Spaniards (56\%). 
No significant difference was observed in late presentation and advanced disease in the sub-Saharan Africans (63\% and $43 \%$, respectively), non-sub-Saharan immigrants (66\% and 53\%), and Spaniards (59\% and 38\%). During the first 6 months of diagnosis, tuberculosis was the most predominant AIDS-related disease in the sub-Saharans compared to pneumonia due to Pneumocystis jiroveci in the rest of the patients.

\section{Evolution data during monitoring}

A median of 27 new diagnoses per year was produced, with a slight decline in recent years. The percentage of immigrants varied according to the year of diagnosis (up to $75 \%$ in 2009 with a subsequent decline). During monitoring, the age at diagnosis showed an increasing trend from 32-33 years from 2004-2005 to 34-35 years from 2011-2012.

\section{Factors related to a delayed diagnosis}

The factors associated with a greater risk of late presentation in the multivariate analysis were an older age at diagnosis and heterosexual transmission, whereas diagnosis and screening for pregnancy played protective roles (Table 3). The only factor associated with a greater risk of presenting advanced disease was an older age (Table 4). In the multivariate analysis stratified by sex, only among male patients an association was found between late presentation and immigrant origin (OR 2.9; p 0.01).

\begin{tabular}{|c|c|c|c|c|c|c|}
\hline \multirow{2}{*}{ Variables } & \multicolumn{3}{|c|}{ Univariate analysis } & \multicolumn{3}{c|}{ Multivariate analysis } \\
\cline { 2 - 7 } & OR & $95 \% \mathrm{CI}$ & $\mathrm{p}$ & $\begin{array}{c}\text { OR } \\
\text { adjusted }\end{array}$ & $95 \% \mathrm{CI}$ & $\mathrm{p}$ \\
\hline Age at diagnosis & 1.05 & $1.02-1.1$ & 0.001 & 1.08 & $1-1.2$ & 0.03 \\
\hline Sex (male vs. female) & 0.99 & $0.6-1.8$ & 0.98 & 0.83 & $0.35-1.9$ & 0.7 \\
\hline Origin (Immigrant vs. Spanish) & 1.23 & $0.7-2.1$ & 0.5 & 1.27 & $0.6-2.8$ & 0.6 \\
\hline Pregnancy diagnosis & 0.2 & $0.07-0.6$ & 0.003 & 0.14 & $0.04-0.5$ & 0.002 \\
\hline $\begin{array}{c}\text { Transmission route } \\
\text { (Hetero vs. MSM) }\end{array}$ & 1.71 & $0.9-3.2$ & 0.09 & 14.5 & $0.7-294$ & 0.08 \\
\hline
\end{tabular}

Hetero: heterosexual relationships; MSM: men who have sex with men

*The transmission routes of injected drug users and other risks were not included in the multivariate analysis due to their underrepresentation Table 3: Multivariate analysis of the variables associated with late presentation

\begin{tabular}{|c|c|c|c|c|c|c|}
\hline \multirow{2}{*}{ Variables } & \multicolumn{3}{|c|}{ Univariate analysis } & \multicolumn{3}{c|}{ Multivariate analysis } \\
\cline { 2 - 7 } & OR & $95 \% \mathrm{CI}$ & $\mathrm{p}$ & $\begin{array}{c}\text { OR } \\
\text { adjusted }\end{array}$ & $95 \% \mathrm{CI}$ & $\mathrm{p}$ \\
\hline Age at diagnosis & 1.05 & $1.02-1.1$ & 0.001 & 1.03 & $1-1.07$ & 0.02 \\
\hline Sex (male vs. female) & 1.5 & $0.8-2.7$ & 0.17 & 0.34 & $0.07-1.7$ & 0.18 \\
\hline Origin (Immigrant vs. Spanish) & 1.37 & $0.8-2.4$ & 0.26 & 0.36 & $0.08-1.7$ & 0.2 \\
\hline Pregnancy diagnosis & 0.24 & $0.07-0.8$ & 0.03 & 0.42 & $0.1-1.7$ & 0.23 \\
\hline $\begin{array}{c}\text { Transmission route } \\
\text { (Hetero vs. MSM) }\end{array}$ & 1.9 & $1-3.6$ & 0.05 & 1.56 & $0.7-3.6$ & 0.3 \\
\hline
\end{tabular}

Hetero: heterosexual relationships; MSM: men who have sex with men

*The transmission routes of injected drug users and other risks were not included in the multivariate analysis due to their underrepresentation Table 4: Multivariate analysis of the variables associated with advanced disease presentation

\section{Antiretroviral treatment}

Antiretroviral therapy was initiated in $75 \%$ of the patients. Initiation was delayed in $50 \%$ of the patients, with no difference between the immigrants $(55 \%)$ and Spaniards (44\%), but was more common among the immigrant men $(66 \%$ vs. $39 \%$ in Spaniards; $\mathrm{p}=$ $0.004)$ and the Spanish women ( $88 \%$ vs. $41 \%$ in immigrants; $\mathrm{p}=0.01)$.

No difference was observed in the virologic response between the immigrants and the Spaniards, but a trend toward a worse immune response was observed in the immigrants, especially in the sub-Saharans (data not shown). No difference was observed in the treatment response according to HIV subtype. Interruption of treatment tended to be higher in the immigrants than in the Spaniards (57\% vs. $46 \%$ ), especially in the sub-Saharans (65\%).

\section{Loss to follow-up}

A total of $33 \%$ of the new diagnoses were lost to follow-up, including more immigrants (43\%), especially sub-Saharans (46\%), than 
Spaniards $(20 \%)(\mathrm{p}<0.001)$ (Figure 1). The factors associated with a greater risk of loss to follow-up in the multivariate analysis were a younger age at diagnosis and heterosexual transmission (Table 5).

\section{Survival Functions}

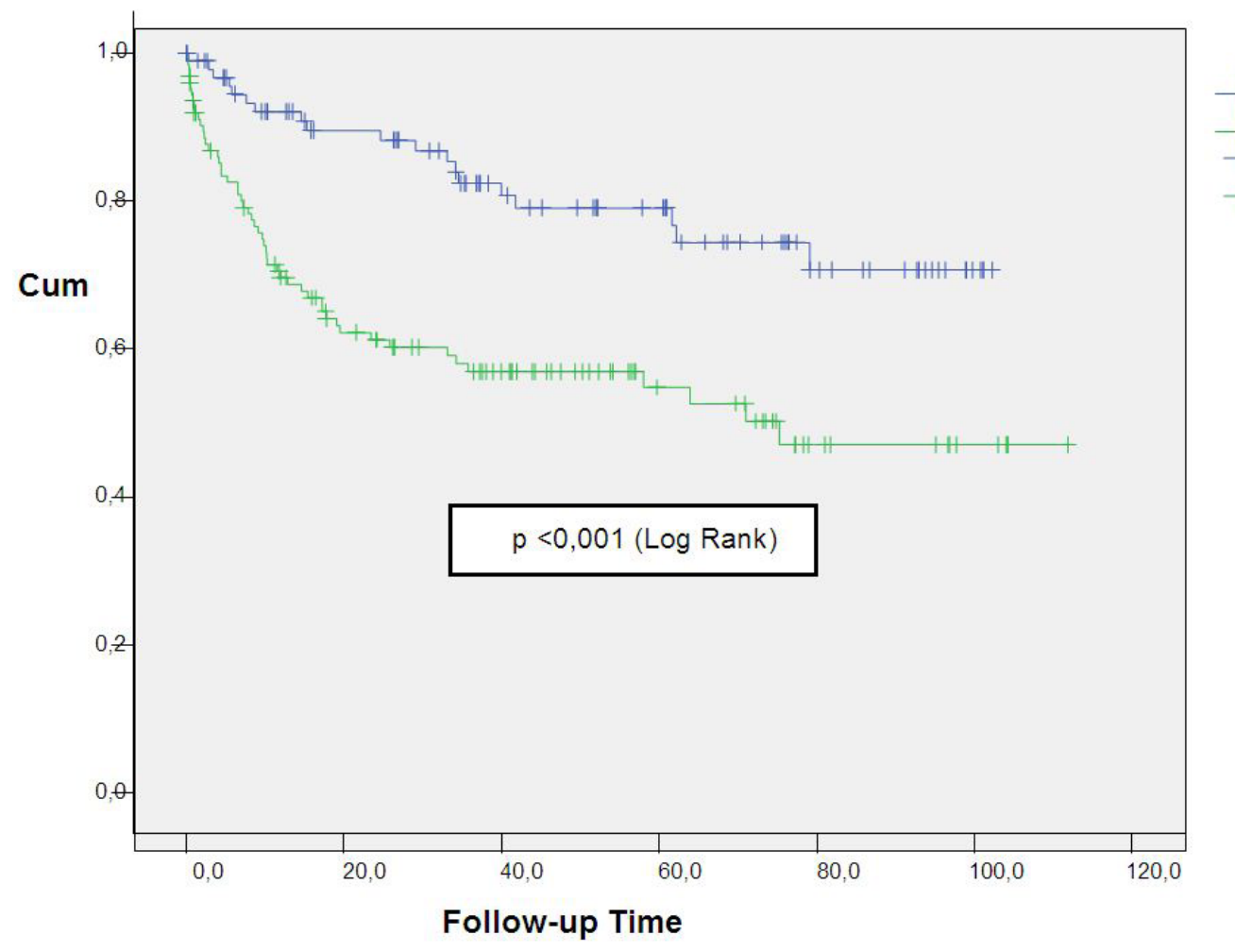

Origin

Immigrant

Spanish-censored

Immigrant-censored

\section{Survival Functions}

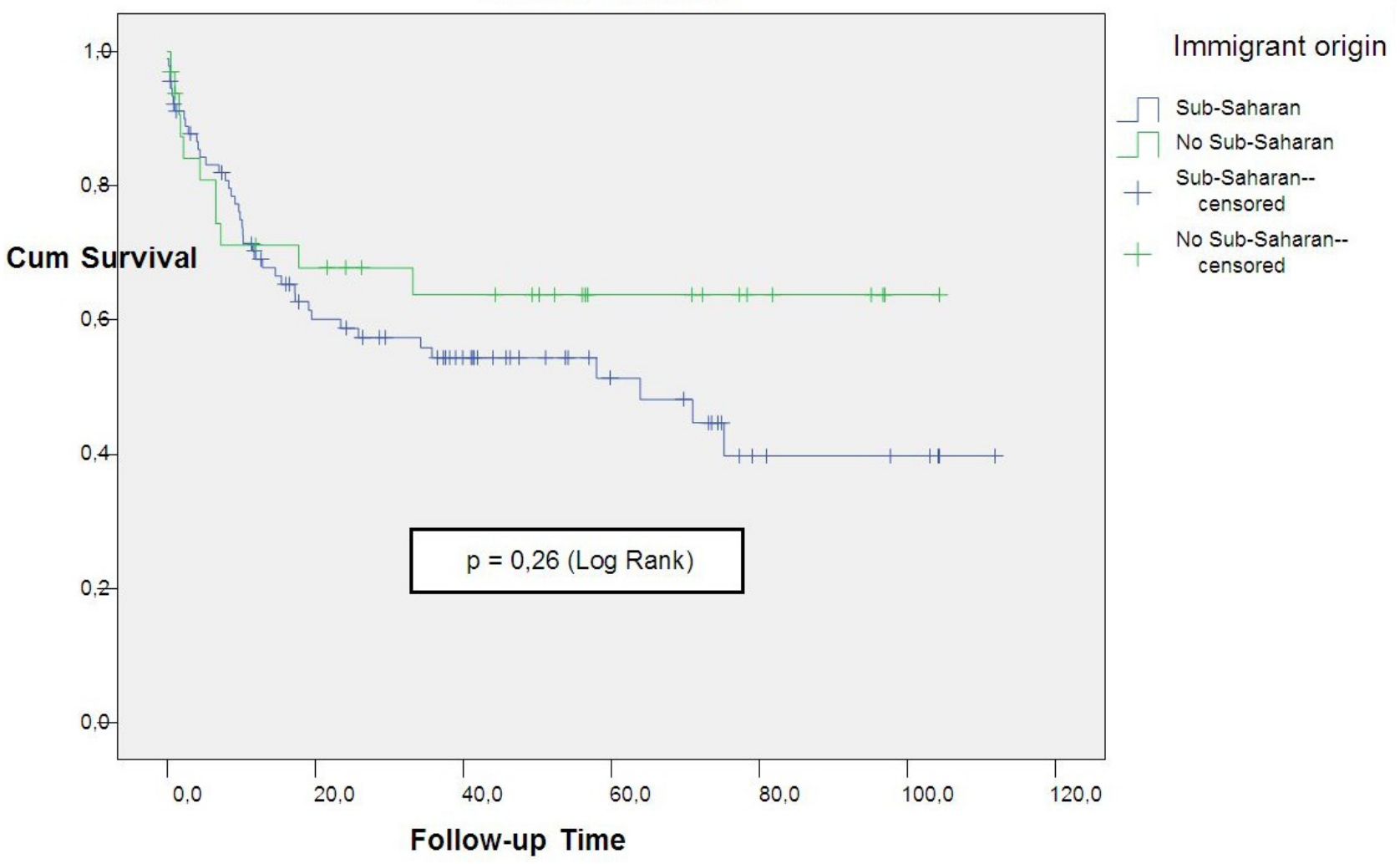

Figure 1: Time to loss to follow-up (weeks) according to the origin of the patients with new HIV diagnoses 


\begin{tabular}{|c|c|c|c|c|c|c|}
\hline \multirow{2}{*}{ Variables } & \multicolumn{3}{|c|}{ Univariate analysis } & \multicolumn{3}{c|}{ Multivariate analysis } \\
\cline { 2 - 7 } & OR & $95 \% \mathrm{CI}$ & $\mathrm{p}$ & $\begin{array}{c}\text { OR } \\
\text { adjusted }\end{array}$ & $95 \% \mathrm{CI}$ & $\mathrm{p}$ \\
\hline Age at diagnosis & 0.97 & $0.9-1$ & 0.07 & 0.96 & $0.9-1$ & 0.02 \\
\hline Late presentation & 0.53 & $0.3-0.95$ & 0.03 & 0.67 & $0.1-3.1$ & 0.6 \\
\hline Advanced HIV Presentation & 0.68 & $0.4-1.2$ & 0.2 & ------ & ------ & ------ \\
\hline Sex (male vs. female) & 0.61 & $0.3-1.1$ & 0.1 & 1.49 & $0.7-3.4$ & 0.3 \\
\hline Origin (Immigrant vs. Spanish) & 2.99 & $1.6-5.5$ & $<0.001$ & 1.04 & $0.3-4.1$ & 0.96 \\
\hline $\begin{array}{c}\text { Transmission route } \\
\text { (Hetero vs. MSM) }\end{array}$ & 2.49 & $1.2-5$ & 0.01 & 7.9 & $1.7-36$ & 0.007 \\
\hline
\end{tabular}

Hetero: heterosexual relationships; MSM: men who have sex with men

*The transmission routes of injected drug users and other risks were not included in the multivariate analysis due to their underrepresentation

Table 5: Multivariate analysis of the variables associated with loss to follow-up

In the multivariate analysis including only males, however, immigrant origin was associated with lost to follow-up (Table 6).

\begin{tabular}{|c|c|c|c|c|c|c|}
\hline \multirow{2}{*}{ Variables } & \multicolumn{3}{|c|}{ Univariate analysis } & \multicolumn{3}{c|}{ Multivariate analysis } \\
\cline { 2 - 7 } & OR & $95 \% \mathrm{CI}$ & $\mathrm{p}$ & $\begin{array}{c}\text { OR } \\
\text { adjusted }\end{array}$ & $95 \% \mathrm{CI}$ & $\mathrm{p}$ \\
\hline Age at diagnosis & 0.98 & $0.9-1$ & 0.3 & 0.96 & $0.9-1.01$ & 0.15 \\
\hline Late presentation & 0.59 & $0.3-1.2$ & 0.16 & 0.56 & $0.2-1.4$ & 0.21 \\
\hline Advanced HIV Presentation & 0.72 & $0.3-1.5$ & 0.4 & ------ & ------ &.---- \\
\hline Origin (Immigrant vs. Spanish) & 3.19 & $1.5-6.7$ & 0.002 & 3.03 & $1.2-7.9$ & 0.02 \\
\hline $\begin{array}{c}\text { Transmission route } \\
\text { (Hetero vs. MSM) }\end{array}$ & 2.4 & $1.1-5.3$ & 0.03 & 2.47 & $0.9-6.7$ & 0.08 \\
\hline
\end{tabular}

Hetero: heterosexual relationships; MSM: men who have sex with men

${ }^{*}$ The transmission routes of injected drug users and other risks were not included in the multivariate analysis due to their underrepresentation

Table 6: Multivariate analysis of the variables associated with loss to follow-up in male patients

\section{Mortality}

A total of 7 deaths occurred among the new diagnoses (3.2\%), including 5 Spanish men, 1 Spanish woman, and 1 Moroccan woman. Death was more frequent among Spaniard than immigrant patients ( $6,3 \%$ vs $0,8 \%$; 0,02$)$, without significant difference according to origin of immigrants.

The median age was 51 years (range $45-55$ years). The 5 deaths with CD 4 counts $<200$ cells/ $\mu$ lat diagnosis $(4$ with CD $4<50$ cells/ $\mu \mathrm{l})$ presented an AIDS-defining disease in the first 6 months. In 6 of the 7 patients, the cause of death was an opportunistic disease.

\section{Discussions}

More than half of the new HIV diagnoses (57\%) in our cohort were immigrants, and predominantly from SSA (42\%). This figure was much higher than is typically observed in other Spanish areas [14] with some exceptions [15]. Immigrants of sub-Saharan origin represented almost two-thirds of the total immigrants. This was very different from the proportions found in other Spanish cohorts in which Latin American immigrants predominated and was more similar to other European series [4,5]. As a result, non-B HIV subtypes were much more frequent in our study than in other studies $[8,16,17]$.

The sub-Saharan patients were the only group in which women and heterosexual transmission predominated, which has been observed in many studies $[4,10,14]$.

In our series, the immigrant women were diagnosed at a younger age than the Spanish women, which was similar to other series [5] that reported diagnoses at a younger age among immigrants $[4,10]$ and women [6].

The high percentage of delayed diagnosis among patients in our cohort was higher than in most studies in Spain [3,6,7,18-20]. In some cases, this difference can be explained by the definition of delayed diagnosis or differences in the study period. In the European COHERE study, which used the same definition, the delayed diagnosis figures were also lower but were higher in the countries of southern Europe [21].

The immigrant men and Spanish women subgroups were the most affected by delayed diagnosis in our series. The difference between the studies may be due to the different origins of the immigrants. In the majority of the studies in Spain and Europe, immigrants, especially Africans, are diagnosed later than the autochthonous population [4-7,14,21,22]. When we analyzed only the sub-Saharan subset, the delayed diagnosis results from Spain were similar to those of our study [3]. In the Swiss cohort [4], men among the sub-Saharans also presented lower baseline CD4 counts than the women. 
Although access to the health system in our country is universal, the precarious situation of many immigrants and the linguistic and cultural differences hinder access. Thus, these populations often do not seek medical care until they feel ill [5]. The subSaharans constitute an especially vulnerable population, with a poor education level, greater lack of knowledge about the health system and stigmatization [23].

The factors independently associated with a delayed diagnosis in our study were an older age and being a male immigrant with heterosexual transmission, whereas diagnosis and screening for pregnancy was a protective factor. This association has also been found in other studies $[6,7,14,19,21]$ in addition to a lower level of education (a surrogate marker of socioeconomic status) [24,25]. In a study in London, a sub-Saharan origin was associated with a two-fold higher risk of diagnosis with advanced disease than the natives after adjusting for gender and risk group [5]. Similar to other studies [6,7], the association of a delayed diagnosis with age was lower in the women and the immigrants in our cohort, whereas the association with the male sex and heterosexual transmission was higher among the immigrants.

The increase in the delayed diagnosis only among male and not among female immigrants in our study was explained by the high percentage of women diagnosed during screening for pregnancy (30\%), all of whom were sub-Saharan, were younger, and had more children than the Spanish subgroup. Compared to homosexual males in which HIV testing is habitual [3], the lower perception of risk in heterosexual men and women may explain their greater delayed diagnosis. However, HIV screening should have being conducted among the heterosexual male immigrants in our cohort because the majority are sub-Saharans (originating from areas of high prevalence) but they don 't access easily to the health system.

Although some studies have observed a decrease in delayed diagnosis over time $[6,14,20]$, this trend remained stable in other studies, including ours [19,21]. This decline has only been demonstrated among homosexuals [3,6,14] and not among subSaharans [5], and an increase has been observed among women infected through heterosexual transmission in the countries of southern Europe [21].

The initiation of treatment was delayed more often in the immigrant men and Spanish women in our study; these subgroups coincided with a greater diagnosis delay. In a Spanish study [26], delayed initiation of treatment was associated with an older age, being male, and lower education level and socioeconomic status. The tendency toward a worse immunological response among our sub-Saharan immigrants has been observed in other studies.

In our cohort, one-third of the new diagnoses were lost to follow-up. This figure was higher than that of other series, perhaps due to the inclusion of patients with a single visit. Similar to other studies [10], immigrants had a higher proportion of lost to followup compared to Spaniards. In the adjusted analysis this factor did not remain significant, and only a younger age at diagnosis and the heterosexual transmission route were factors associated with loss to follow-up. This trend was also observed in other cohorts together with the consumption of intravenous drugs, a low education level, and a higher CD4 count at diagnosis [27,28]. Most of SSA immigrants had adquired the HIV infection by heterosexual transmission, and in our study being male immigrant was associated with lost to follow-up.

Late presentation is associated with an increased incidence of AIDS and death, especially in southern European countries [21]. Similar to other cohorts, the AIDS-defining disease most common among our sub-Saharan patients was tuberculosis [4,22]. The leading cause of death in our study was opportunistic diseases, which contrasted with other current studies in which patients died primarily due to non-AIDS events [29]. Death was more frequent among Spaniard patients, perhaps because of frequent losses to follow-up of immigrants.

Our study has limitations. First, this study is a retrospective study; however, the information bias was small because the study used a database collected prospectively and the majority of the variables were collected as part of routine clinical practice. The findings of the study coincided with the findings described by other authors, which supported its external validity. Because the study was conducted in a single hospital, our data cannot be generalized to other areas where the epidemiological characteristics of the patients vary significantly. With less contact of the sub-Saharan immigrants with the health system, we can assume that we have diagnosed only the more seriously ill patients. Additionally, the frequent losses to follow-up can lead to a worse assessment of monitoring, including mortality. However, the monitoring period in our study was long (covering 9 years) and included a high percentage of sub-Saharan immigrants, which were less frequent in other Spanish cohorts. This phenomenon permitted us to study their characteristics in depth.

\section{Conclusions}

Delayed diagnosis was very frequent in our cohort with large numbers of sub-Saharan immigrants, especially among the subSaharan immigrant men and Spanish women; both groups had older ages and heterosexual transmission. The loss to follow-up was higher among the sub-Saharan immigrants. In view of these data, we believe that the current screening of HIV infection [30] is not sufficient to achieve control of the epidemic. Prevention campaigns are necessary and should be oriented at increasing the perception of risk in the general population (heterosexual transmission) and among the sub-Saharans [23]. 


\section{Acknowledgements}

The authors thank Ms. Paloma González Pérez for helping with consultation patient care.

\section{Conflict of interests}

This study has received funding from the "Red de Investigación Cooperativa en Enfermedades Tropicales (RICET + RD12/0018/0008) [Network for Cooperative Research in Tropical Diseases], National Plan VI of I+D+I 2008-2011, Instituto de Salud Carlos III [Carlos III Institute of Health] - Cooperative General Sub-Directorate of Networks and Research Centers cofinanced by the Fondo Europeo de Desarrollo Regional (fondos FEDER) [European Regional Development Fund (ERDF funds)].

\section{References}

1. Progress of the municipal roster up to January 1, 2013 Statistics National Institute. Population (Spanish / foreign) by place of birth and sex and Foreign population by country of birth, age (quinquennial groups) and sex.

2. Diez M, Diaz A, Garriga C, Pons M, Ten A, et al. (2014) The Hospital Survey Study Group. A low-cost, sustainable, second-generation system for surveillance of people living with HIV in Spain: 10-year trends in behavioral and clinical indicators, 2002 to 2011. Euro Surveill 19.

3. HIV Vigilance area, behaviors and risks: System of information on new diagnoses of HIV and National Registry of AIDS cases.

4. Staehelin C, Rickenbach M, Low N, Egger M, Ledergerber B, et al. (2003) Migrants from Sub-Saharan Africa in the Swiss HIV cohort Study: access to antiretroviral therapy, disease progression and survival. AIDS 17: 2237-44.

5. Boyd AE, Murad S, O'Shea S, de Ruiter A, Watson C, et al. (2005) Ethnic differences in stage of presentation of adults newly diagnosed with HIV-1 infection in south London. HIV Med 6: 59-65.

6. Olivaa J, Galindoa S, Vivesb N, Arrillagac A, Izquierdod A, et al. (2010) Delayed diagnosis of HIV infection in Spain. Enferm Infecc Microbiol Clin 28: 583-9.

7. Oliva J, Díez M, Galindo S, Cevallos C, Izquierdo A, et al. (2014) Predictors of advanced disease and late presentation in new HIV diagnoses reported to the surveillance system in Spain. Gac Sanit 28: 116-22.

8. Yebra G, Rivas P, Herrero MD, López M, de Mulder M, et al. (2009) Clinical Differences and Viral Diversity between Newly HIV Type 1-Diagnosed African and Non-African Patients in Spain (2005-2007). AIDS Res Hum Retroviruses 25: 37-44.

9. Teira R, Suárez-Lozano I, Muñoz P, Viciana P, Lozano F, et al. (2005) Epidemiological Pattern of HIV infection in 15 Spanish Hospitals: Cases on new diagnoses included in the VACH cohort in 2001 and 2002. Enferm Infecc Microbiol Clin 23: 213-7.

10. Pérez-Molina JA, Mora M, Suárez-Lozano I, Casado JL, Teira R, et al. (2010) Do HIV-Infected Immigrants Initiating HAART have Poorer Treatment-Related Outcomes than Autochthonous Patients in Spain? Results of the GESIDA 5808 Study. Curr HIV Res 8: 521-30.

11. Waters L, Fisher M, Anderson J, Wood C, Delpech V, et al. (2011) Responses to highly active antiretroviral therapy and clinical events in patients with a low CD4 cell count: late presenters vs. late starters. HIV Med 12: 289-98.

12. Grinsztejn B, Hosseinipour MC, Ribaudo HJ, Swindells S, Eron J, et al. (2014) Effects of early versus delayed initiation of antiretroviral treatment on clinical outcomes of HIV-1 infection: results from the phase 3 HPTN 052 randomised controlled trial. Lancet Infect Dis 14: 281-90.

13. Antinori A, Coenen T, Costagiola D, Dedes N, ellefson M, et al. (2011) Late presentation of HIV infection: a consensus definition. HIV Med 12: 61-4.

14. Vives N, Carnicer-Pont D, García de Olalla P, Camps N, Esteve A, et al. (2012) Factors associated with late presentation of HIV infection in Catalonia, Spain. Int J STD AIDS 23: 475-80.

15. Condes E, Barros C, Merino F, Ruiz-Galiana J (2010) HIV infection in adults: epidemiological changes over 25 years (1983-2008). Enferm Infecc Microbiol Clin 28: 156-61.

16. Treviño A, Soriano V, Rodríguez C, Arredondo M, Rivas P, et al. (2011) Changing Rate of Non-B Subtypes and Coinfection with Hepatitis B/C Viruses in Newly Diagnosed HIV Type 1 Individuals in Spain. AIDS Res Hum Retroviruses 27: 633-8.

17. Holguín A, de Mulder M, Yebra G, López M, Soriano V (2008) Increase of Non-B Subtypes and Recombinants Among Newly Diagnosed HIV-1 Native Spaniards and Immigrants in Spain. Current HIV Res 6: 327-34.

18. Jaén A, Casabona J, Esteve A, Miró JM, Tural C, et al. (2005) Clinical-epidemiological characteristics and antiretroviral treatment trends in a cohort of HIV infected patients. The PISCIS Project Med Clin (Barc) 124: 525-31.

19. Mínguez-Gallego C, Vera-Remartinez EJ, Albert-Coll M, Roldán-Puchalt MC, Aguilar-Climent M, et al. (2015) Change in the clinical-epidemiological characteristics of new cases of infection by HIV-1 in Castellon (Spain) and its repurcussion in late diagnosis (1987-2011). Enferm Infecc Microbiol Clin 33: 173-80.

20. López A, Palacios R, Merino D, Santos J, Sociedad Andaluza de Enfermedades Infecciosas (2011) Diagnostic delay in HIV in Andalucia Enferm Infecc Microbiol Clin 29: 639-40.

21. Mocroft A, Lundgren JD, Sabin ML, Monforte AD, Brockmeyer N, et al. (2013) Risk Factors and Outcomes for Late Presentation for HIV-Positive Persons in Europe: Results from the Collaboration of Observational HIV Epidemiological Research Europe Study (COHERE). PloS Med 10: e1001510.

22. Monge S, Alejos B, Dronda F, del Romero J, Iribarren JA, et al. (2013) Inequalities in HIV disease management and progression in migrants from Latin America and sub-Saharan Africa living in Spain. HIV Medicine 14: 273-83.

23. Navaza B, Guionnet A, Navarro M, Estévez L, Pérez-Molina JA, et al. (2012) Reluctance To Do Blood Testing Limits HIV Diagnosis and Appropriate Health Care of Sub-Saharan African Migrants Living in Spain. AIDS Behav 16: 30-5.

24. The Socio-economic Inequalities and HIV Writing Group for Collaboration of Observational HIV Epidemiological Research in Europe (COHERE) in EuroCoord, Lodi S, Dray-Spira R, Touloumi G, Braun D, Teira R, et al. (2014) Delayed HIV diagnosis and initiation of antiretroviral therapy: inequalities by educational level, COHERE in EuroCoord. AIDS 28: 2297-306.

25. Sobrino-Vegas P, Rodriguez-Urrego J, Berenguer J, Caro-Murillo AM, Blanco JR, et al. (2012) Educational gradient in HIV diagnosis delay, mortality, antiretroviral treatment initiation and response in a country with universal healthcare. Antivir Ther 17: 1-8.

26. Pérez-Molina JA, Suárez-Lozano I, del Arco A, Teira R, Bachiller P, et al. (2011) Late Initiation of HAART Among HIV-Infected Patients in Spain Is Frequent and Related to a Higher Rate of Virological Failure but not to Immigrant Status. HIV Clin Trials 12: 1-8. 
27. Sobrino-Vegas P, Gutiérrez F, Berenguer J, Labarga P, García F, et al, CoRIS. (2011) The cohort of the spanish hiv research network (coris) and its associated biobank; organizational issues, main findings and losses to follow-up. Enferm Infecc Microbiol Clin 29: 645-53.

28. Diaz A, Ten A, Marcos H, Gutiérrez G, González-García J, et al. (2015) Factors determining irregular attendance to follow-up visits among human immunodeficiency virus patients: Results of the hospital survey of patients infected with human immunodeficiency virus. Enferm Infecc Microbiol Clin 33: 324-30.

29. López C, Masiá M, Padilla S, Aquilino A, Bas C, et al. (2016) Deaths due to non-AIDS diseases among HIV infected patients: A 14-year study (1998-2011). Enferm Infecc Microbiol Clin 34: 222-7.

30. Ministry of Health, social services and equality (2014) Guidelines for early detection of HIV in the health system. Reports, studies and research 2014. Reviewed 10 Ago 2014.

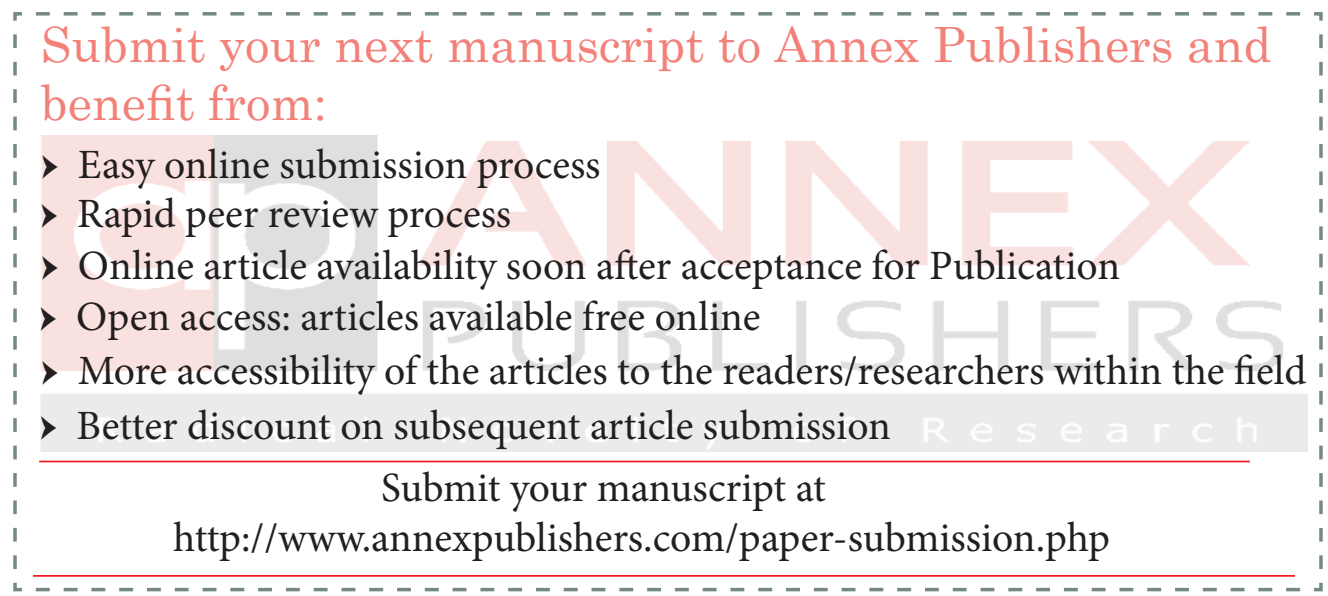

